\title{
Coronary sinus of valsalva dissection with intracusp haematoma
}

\author{
Habib Khan, Sanjay Chaubey, Olaf Wendler, Lindsey John \\ Cardiothoracic Department, King's College Hospital, London, UK
}

Correspondence to Mr Olaf Wendler, hkhan1@nhs.net

\section{DESCRIPTION}

Retrograde dissection of the coronary sinus of valsalva (CSV) is a rare yet life-threatening complication during primary coronary intervention (PCI). We report a case of a 73-year-old male, who presented with an inferior myocardial infarction. The patient was loaded with aspirin 300 $\mathrm{mg}$ and clopidogrel $600 \mathrm{mg}$ as per hospital protocol without any glycoprotein IIb/IIIa and taken to catheter suite for PCI. During diagnostic coronary angiography, (figure 1A) on injecting the dye into the right coronary artery (RCA) retrograde flow was observed into the CSV resulting in its dissection (figure 1B). The patient remained haemodynamically stable with no acute ST changes on ECG. The resulting intracusp haematoma was observed to be obstructing the right coronary ostium (figure 1B). Hence to ensure flow down the RCA a bare metal stent was inserted (figure 1C). The patient's aspirin and clopidogrel was withheld and therapeutic enoxapirin was commenced. The patient
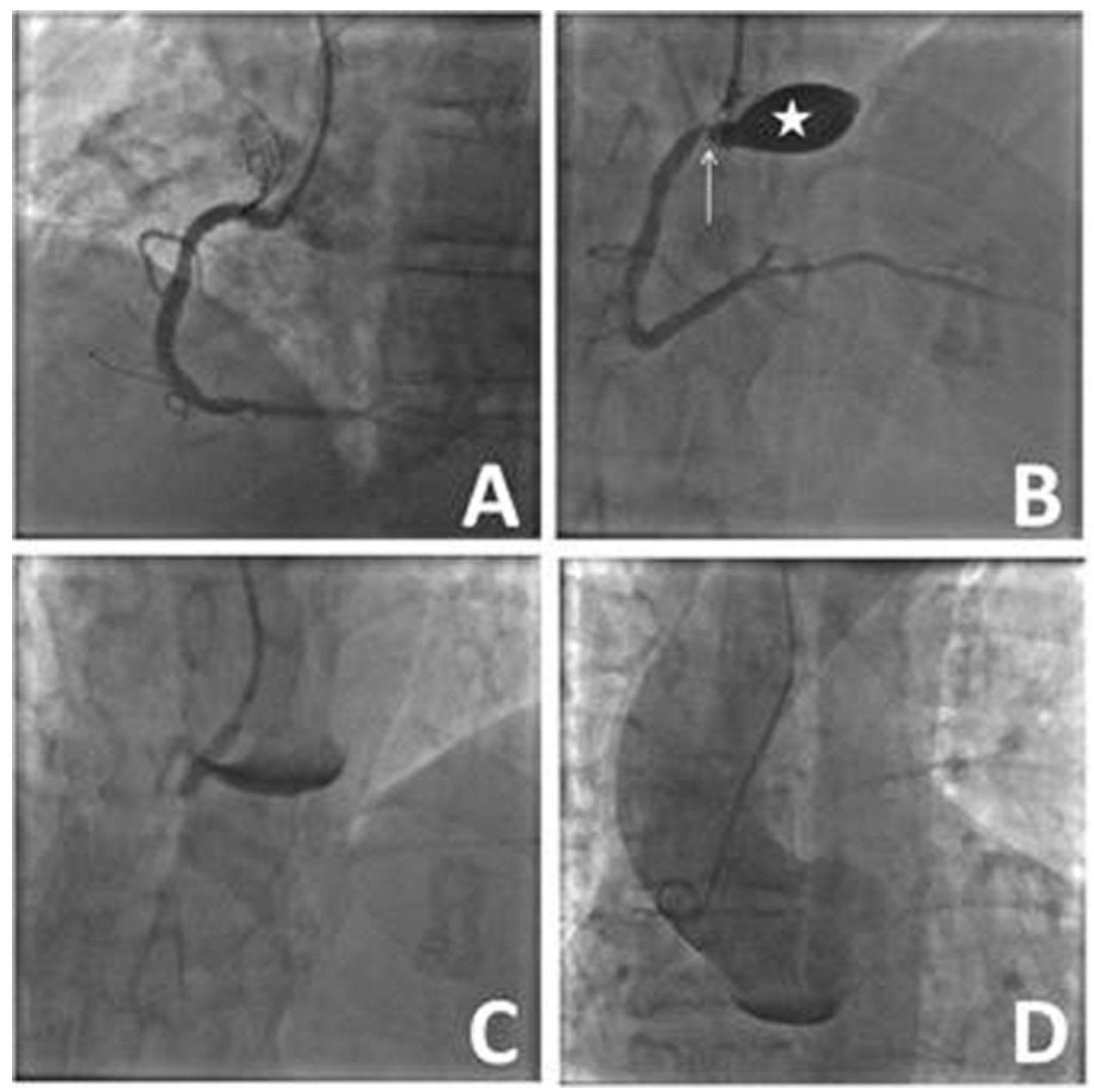

Figure 1 (A) Diagnostic angiogram demonstrating coronary artery disease in the RCA. (B) Subsequent injection and retrograde flow into the sinus of valsalva resulted in its dissection with the formation of an intracusp haematoma (star). This was obstructing the blood flow into the RCA ostium (arrow). (C) A bare metal stent was deployed to ensure adequate flow down the RCA. (D) Final aortogram shows a resolving intracusp haematoma with residual dye in the sinus of valsalva. 


\section{BMJ Case Reports}

was taken to theatre for coronary artery bypass grafting (CABG) for the pre-existing coronary artery disease present in his native vessels. He made a satisfactory post operative recovery and was discharged home on the fifth post operative day. Retrograde dissection of the CSV is more commonly observed in the RCA and the right CSV. The exact mechanism of injury is unknown but direct intimal injury, guidewire preinflation, over-forceful dye injection, medial degeneration and shearing forces during systole and diastole have been mentioned in the literature. ${ }^{1}$ The management of these cases is dependent on the emergent nature of the complication. Some reports in the literature describe a conservative approach. However such patients tend to have a poorer outcome. ${ }^{2}{ }^{3}$ Coronary stenting and surgery are the two favoured options. Immediate stenting prevents the propagation of the dissection antegrade into the RCA and retrograde into the aortic root and ascending aorta. Reports in the literature describe the successful surgical correction in patients in whom the dissection has progressed. As our patient was stable with no progressive dissection antegrade or retrogradely he was initially managed with stenting to the dissection. A planned CABG was then undertaken for his pre-existing triple vessel coronary artery disease.

\section{Competing interests None.}

Patient consent Obtained.

\section{REFERENCES}

1. Goldberg N, Krasnow N. Sinus of Valsalva aneurysms. Clin Cardiol 1990;13:831-6.

2. Yip HK, Wu CJ, Yeh KH, et al. Unusual complication of retrograde dissection to the coronary sinus of valsalva during percutaneous revascularization: a single-center experience and literature. Chest 2001;119:493-501.

3. Pérez-Castellano N, García-Fernández MA, García EJ, et al. Dissection of the aortic sinus of Valsalva complicating coronary catheterization: cause, mechanism, evolution, and management. Cathet Cardiovasc Diagn 1998;43:273-9.

This pdf has been created automatically from the final edited text and images.

Copyright 2011 BMJ Publishing Group. All rights reserved. For permission to reuse any of this content visit http://group.bmj.com/group/rights-licensing/permissions. BMJ Case Report Fellows may re-use this article for personal use and teaching without any further permission.

Please cite this article as follows (you will need to access the article online to obtain the date of publication).

Khan H, Chaubey S, Wendler O, John L. Coronary sinus of valsalva dissection with intracusp haematoma. BMJ Case Reports 2011; 10.1136/bcr.08.2011.4708, date of publication

Become a Fellow of BMJ Case Reports today and you can:

- Submit as many cases as you like

- Enjoy fast sympathetic peer review and rapid publication of accepted articles

- Access all the published articles

- Re-use any of the published material for personal use and teaching without further permission

For information on Institutional Fellowships contact consortiasales@bmjgroup.com

Visit casereports.bmj.com for more articles like this and to become a Fellow 